\title{
NECESIDAD DE UNIFICACIÓN DE NORMAS SUSTANCIALES Y PROCESALES EN EL EJERCICIO DEL IUS PUNIENDI FRENTE A MENORES INFRACTORES EN COLOMBIA*
}

\author{
Need for unification of substantial and procedural rules in the \\ exercise of the right to punish of children in Colombia offenders
}

Sergio Andrés Caballero Palomino**

Katerin Yulieth Cruz Cadena ***

Daniel Fabián Torres Bayona****

Recepción: 29 de enero de 2018. Aceptación: 10 de mayo de 2018.

DOI: http://dx.doi.org/10.21017/Rev.Repub.2018.v25.a50

\section{RESUMEN}

El Código de la Infancia y la Adolescencia señala sanciones para los menores infractores en Colombia, las cuales son ambiguas y además para su aplicación el intérprete debe remitirse al Código Penal, Código de Procedimiento Penal, Normas de Derecho Internacional, entre otras, generando en muchas ocasiones dificultad para el análisis, aplicación de la norma sustancial, tasación de

* Artículo producto de trabajo colaborativo desarrollado desde el proyecto de investigación: Necesidad de unificación de normas sustanciales y procesales en el ejercicio del ius puniendi frente a menores infractores en Colombia. 2015.

* Maestrando en Derecho del Estado con Énfasis en Derecho Público de la Universidad Externado de Colombia. Especialista en Derecho Administrativo. Abogado. Integrante del Grupo «Pensamiento Jurídico», Corporación Universitaria de Ciencia y Desarrollo, Uniciencia. Par académico del Ministerio de Educación Nacional. Docente investigador Uniciencia, Bogotá. ORCID nro. 0000-0003-4715-8537. Correo electrónico: abogadosergio caballero@hotmail.com.

*** Especialista en Derecho Penal y Criminología. Abogada de las Universidad del Atlántico. Diplomado en Docencia Universitaria. Estudiante de Psicología, Universidad Cooperativa de Colombia, Bogotá. Correo electrónico: abg.katerincruz@hotmail.com

**** Doctorando en Derecho, Universidad Autónoma de Barcelona. Magíster en Derecho con énfasis en Derecho Público, Universidad Externado de Colombia; especialista en Derecho Público, Universidad Autónoma de Bucaramanga; abogado de la Universidad Industrial de Santander; profesor interno (asistente), Línea de Investigación en Neoconstitucionalismo, Grupo en Ciencia Política y Derecho «CIPJURIS», Facultad de Derecho, Escuela de Derecho y Ciencias Políticas, Universidad Pontificia Bolivariana, Seccional Bucaramanga. Área de actuación: Derecho Constitucional. Correo electrónico: daniel.torresb@upb.edu.co. 
penas, uso de procedimientos, entre otras dificultades que se evidencian en la práctica jurídica, especialmente en la etapa de investigación y juzgamiento. Por tanto, en el presente artículo de investigación se desarrollará el siguiente interrogante: ¿Existe la necesidad de unificar las normas sustanciales y procesales para la aplicación de la Ley Penal contra los menores infractores en Colombia? Como conclusión se tiene que al estar dispersas las normas de infancia y adolescencia en distintos códigos, leyes internas, tratados y convenios internacionales, se hace necesario unificar un código donde se integren todas las normas dirigidas a los niños, niñas y adolescentes para así facilitar la interpretación y aplicación en los respectivos procedimientos penales; incluso se tiene que la misma Corte Constitucional y la Procuraduría General de la Nación han exhortado al Congreso de la República para que unifique las normas de infancia y adolescencia.

Palabras clave: menor infractor, Ius Puniendi, normas sustanciales, normas procesales, unificación.

\begin{abstract}
The Childhood and Adolescence Code, establishes penalties for juvenile offenders in Colombia, which are ambiguous and also to implement the interpreter should refer to the Criminal Code, Code of Criminal Procedure, Rules of International Law, among others, often creating difficulty analysis, application of substantial standard pricing penalties, use of procedures, among other difficulties that are evident in legal practice, especially at the stage of investigation and prosecution, therefore in this research paper will develop the next question: Is there a need to unify the substantive and procedural rules for the application of the criminal law against young offenders in Colombia?. In conclusion, it must be to be dispersed standards childhood in different codes, domestic laws, international treaties and agreements, it is necessary to unify a code which integrates all rules aimed at children and adolescents in order to facilitate the interpretation and implementation in the respective criminal proceedings, even has the same Constitutional Court and the Attorney General's Office have urged Congress to unify the rules of childhood and adolescence.
\end{abstract}

Key words: Minor offender, Ius Puniendi, substantive rules, procedural rules, unification.

\title{
INTRODUCCIÓN
}

La Carta Política de 1991, en su artículo segundo, establece entre los fines esenciales del Estado, el de promover la prosperidad general, garantizar la 
efectividad de los principios, derechos y deberes consagrados en la Constitución y asegurar la convivencia pacífica y la vigencia de un orden justo.

Así las cosas, en nuestro Estado Social de Derecho para asegurar la convivencia pacífica y la vigencia de un orden justo es necesaria la intervención del derecho penal desde el ámbito subjetivo y objetivo: el primero que hace referencia a la aplicación de la ley penal en casos particulares, es decir, la potestad punitiva del Estado frente a los asociados; y el segundo, que refiere a la positivización de normas jurídicas sustanciales y procesales, las cuales deben ser respetadas, y contra el trasgresor de las mismas el Estado ejercerá el derecho a castigar.

Ahora bien, el artículo segundo de la Ley 1098 de 2006 trata sobre el objeto de dicha codificación, el cual pretende establecer normas sustanciales y procesales para una protección integral de los niños, niñas y adolescentes, además de garantizar el ejercicio de sus derechos y libertades que se encuentran contenidos en el ámbito internacional, en la Carta Política y en la normatividad interna; así mismo establece una corresponsabilidad que recae sobre la familia, la sociedad y el Estado con relación al menor.

En el ámbito del sistema penal en Colombia los menores no pueden ser procesados por el sistema de responsabilidad de adultos; sin perjuicio de lo anterior, en la Ley 1098 de 2006, en el Libro II, se desarrolla el Sistema de Responsabilidad Penal para Adolescentes, en donde es conceptualizado por el artículo 139 como el conjunto de normas, principios y procedimientos; además señala las autoridades judiciales especializadas y los entes administrativos que rigen o intervienen la investigación y juzgamiento de delitos cometidos por menores entre 14 y 18 años, en el respectivo momento de cometer el hecho punible; $y$ en el artículo seguido se habla de la finalidad del sistema penal para adolescentes, en el cual se encuentran medidas de carácter pedagógico, específico y diferenciado, respecto del sistema de adultos.

Frente a las sanciones que se encuentran en el artículo 177 de la Ley ibidem, se destaca la amonestación, la imposición de reglas de conducta, la prestación de servicios a la comunidad, la libertad asistida, la internación en medio semicerrado y la privación de libertad en centro de atención especializado. Las anteriores sanciones son ambiguas de interpretación para el operador judicial, y carecen de parámetros expresos para su respectiva aplicación a los distintos tópicos de la praxis jurídica. Sumado a esto surge otra problemática en la cual el Código de Infancia y Adolescencia remite al intérprete y al operador judicial a otras normas como es el Código Penal, el Código de Procedimiento Penal, los Tratados y Convenios Internacionales, entre otros; se dificulta así el proceso de responsabilidad para adolescentes y se hace del mismo algo más tedioso y lento. 
Todo lo anterior puede generar una problemática en el momento del análisis, interpretación y aplicación de la norma jurídica a los menores infractores. Por tanto, el presente estudio pretende indagar sobre la necesidad de la unificación y de la claridad de las normas sustanciales y procesales en el ejercicio de la potestad sancionatoria del Estado, dirigido a los menores infractores en Colombia, con el fin de que este proceso sea mucho más rápido y claro.

Planteamiento del problema: ¿Existe la necesidad de unificar las normas sustanciales y procesales para la aplicación de la Ley Penal contra los menores infractores en Colombia? Objetivo general: Determinar la necesidad de la aplicación de las normas sustanciales y procesales en la aplicación de la ley penal a los menores infractores en Colombia.

La metodología, de acuerdo con el enfoque de investigación del presente artículo, es de carácter jurídico cualitativo, pues se orienta en el estudio de la norma sustancial y procesal, su aplicación e interpretación, además de la deficiencia de las mismas y los posibles vacíos que se pueden suscitar por las potenciales omisiones en que se incurren, en este caso en la Ley de Infancia y Adolescencia. Ahora bien, en cuanto al tipo de investigación, esta es de tipo exploratorio, porque el tema en mención ha sido poco estudiado, y frente al objeto de esta investigación no se ha indagado anteriormente; pero además es de tipo descriptivo, porque pretende someter a análisis, si existe o no la necesidad de la unificación de normas para su aplicación en los menores infractores, y así se desea describir en todos sus componentes principales una realidad. Respecto a los métodos a utilizar en la presente investigación se encuentra el deductivo, toda vez que se inicia en el ámbito general, el Código Penal, el Código Procedimiento Penal y los tratados internacionales, y se finaliza en el ámbito particular, cuando se estudian todas las normas aplicadas a un menor infractor; y además se utiliza el método analítico porque se descompone el tema de la aplicación de la ley a los menores infractores, separándolo en normas sustanciales, normas procesales y la aplicación en casos particulares en la praxis jurídica; y finalmente se utiliza el método sintético, el cual reúne todas las partes del análisis para generar una conclusión global luego de haber sido estudiado el tema en todas sus partes.

Respecto de las fuentes primarias de investigación, se utilizarán normas jurídicas tales como la Ley 1098 de 2006, el Código Penal, el Código de Procedimiento Penal, la Constitución Política, normas, convenios y tratados internacionales, y jurisprudencia; como fuente secundaria se utilizará la doctrina nacional e internacional en el caso concreto; finalmente, como fuentes terciarias se utilizarán textos y artículos de investigación de autores que citen a otros autores. Como técnica de recolección de información se utilizarán el análisis de contenido de textos jurídicos y doctrina. 


\section{EL SISTEMA DE RESPONSABILIDAD PENAL PARA ADO- LESCENTES EN COLOMBIA: UNA MIRADA JURÍDICA A SU FUNCIONAMIENTO}

\section{A. Fundamentos Constitucionales del Sistema de Responsabilidad Penal para Adolescentes}

Inicialmente, es de importancia señalar que el sistema jurídico colombiano, de acuerdo con el artículo 1 de la Constitución Política (1991), se encuentra sustentado bajo un tipo de Estado Social de Derecho, es decir que no solo propende por el cumplimiento de las normas jurídicas, sino que se basa en las necesidades de sus asociados, orbitando todo el sistema jurídico-político en la dignidad del ser humano como principal elemento del Estado. Es esta una de las razones por las cuales el derecho contemporáneo considera que a partir de cierta edad, los menores no solo son titulares de derechos con capacidad para ejercerlos por sí mismos, sino que a su vez deben responder ante el incumplimiento de sus deberes y obligaciones, lo que haría que los mismos estén sometidos al poder punitivo del Estado en los acaecimientos en que cometan violaciones a la ley penal, pero siempre bajo el criterio de imputabilidad diferenciada, es decir, de aquella en la que se tiene en cuenta tanto sus condiciones personales como el grado de evolución de sus facultades, en aras de imponerles una medida, no asimilable al tradicional concepto de pena, que pretenderá reintegrarlos a la sociedad; además se tiene en cuenta su edad para hacerlos parte de un proceso penal en su contra, por lo que son procesados los adolescentes que tengan entre catorce (14) y dieciocho (18) años de edad en el momento de cometida la conducta.

Por otra parte, dentro de los fines del Estado se encuentra «garantizar la efectividad de los principios, derechos y deberes consagrados en la Constitución» (Constitución Política, 1991, artículo 2).

Continuando con el desarrollo sistemático de la normatividad Constitucional, es importante resaltar que el artículo 4 Superior señala que la Constitución es norma de normas, y que en cualquier caso de incompatibilidad con alguna norma jurídica, siempre deben primar los postulados Constitucionales. Por tanto, cuando se vea una inconsistencia entre los derechos fundamentales del adolescente y alguna otra norma jurídica, siempre debe prevalecer la protección superior contenida en el Estatuto Superior.

Así las cosas, el artículo 13 de la Carta Política señala el derecho a la igualdad, pero adicionalmente resalta que se debe tener especial protección por las personas que se encuentran en estado de debilidad manifiesta frente a todos los 
demás ciudadanos. Por tanto, los niños, niñas y adolescentes se constituyen como una población sobre la cual las autoridades deben hacer primar un interés superior, concordando esto con el artículo 44 de la Constitución, donde se indica que son derechos fundamentales de los niños:

(...) la vida, la integridad física, la salud y la seguridad social, la alimentación equilibrada, su nombre y nacionalidad, tener una familia y no ser separados de ella, el cuidado y amor, la educación y la cultura, la recreación y la libre expresión de su opinión. Serán protegidos contra toda forma de abandono, violencia física o moral, secuestro, venta, abuso sexual, explotación laboral o económica y trabajos riesgosos. Gozarán también de los demás derechos consagrados en la Constitución, en las leyes y en los tratados internacionales ratificados por Colombia. (Constitución Política, 1991, art. 44)

El artículo 44, ejusdem, adicionalmente indica en su inciso segundo, la corresponsabilidad hacia los menores, que consiste en que la sociedad, la familia y el Estado tienen obligación en asistir y proteger al menor, garantizando su desarrollo integral y el pleno ejercicio de sus derechos. Y finalmente este artículo fija un postulado muy importante, que fundamenta y cimenta el Código de la Infancia y la Adolescencia; refiere a que «los derechos de los niños prevalecen sobre los derechos de los demás». (Constitución Política, 1991, art. 44)

Más adelante, el artículo 45 de la Carta Constitucional señala que el adolescente tiene derecho a la protección y a la formación integral, y de nuevo impone la obligación al Estado y la sociedad de garantizar su participación activa en los organismos públicos y privados que tengan a cargo la protección, educación y progreso de la juventud.

\section{B. Fundamentos Legales del Sistema de Responsabilidad Penal para Ado- lescentes}

Inicialmente es importante resaltar que la finalidad de la Ley 1098 de 2006 es garantizar a los niños, niñas y adolescentes su pleno y armonioso desarrollo para que crezcan en el seno de la familia y la comunidad con amor, felicidad y comprensión.

El artículo segundo de la Ley 1098 de 2006 indica que el objeto de dicho código es establecer normas sustanciales y procesales para la protección de los niños, niñas y adolescentes. Sin perjuicio de lo anterior, se genera una problemática al enunciarse en el artículo 6, ejusdem, las reglas de interpretación y aplicación que el texto señala: 
Las normas contenidas en la Constitución Política y en los tratados o convenios internacionales de Derechos Humanos ratificados por Colombia, en especial la Convención sobre los Derechos del Niño, harán parte integral de este Código, y servirán de guía para su interpretación y aplicación. En todo caso, se aplicará siempre la norma más favorable al interés superior del niño, niña o adolescente. (Ley 1098, 2006, art. 6)

Con la implementación de la Ley 1098 de 2006, se equipararon los conceptos que acerca de la responsabilidad penal de los menores y de su imputabilidad diferenciada habían desarrollado los tratados e instrumentos internacionales.

El Pacto Internacional de Derechos Civiles y Políticos, adoptado por la Asamblea General de la ONU el 16 de diciembre de 1966 y aprobado en Colombia por la Ley 74 de 1968, consagra que los Estados adoptarán las medidas necesarias para proteger a los niños en razón de su condición de menores, a la vez que prohíbe imponerles la pena de muerte cuando infrinjan la ley penal y les garantiza, en dichos casos, un tratamiento diferente, rápido y eficaz, así como separado de los adultos, cuyo único propósito será el de la readaptación social. También exige que se les respete la privacidad a lo largo de todo el proceso, incluso por encima del principio de publicidad de las actuaciones judiciales.

Al igual que el anterior tratado, la Convención Americana sobre Derechos Humanos o Pacto de San José (1969), aprobada en Colombia por la Ley 16 de 1972, prevé la protección integral a favor de los menores, la prohibición de la pena capital y la obligación de brindarles a los infractores un trato especial y apartado de los mayores de edad, mediante una justicia especializada e impartida con celeridad.

Además, la Convención sobre los Derechos del Niño (1989), promulgada por la ONU y aprobada en Colombia por la Ley 12 de 1991, confiere, además de los derechos ya mencionados, la prohibición de tratos crueles o degradantes y el reconocimiento de las garantías tradicionales del debido proceso. Sumado a lo anterior, impone a favor del adolescente otros derechos derivados de su condición de menor, como la obligación de tener en cuenta su edad y situación particular, la de observar que la reacción del Estado guarde proporción con la infracción cometida por el adolescente, y la de adoptar medidas distintas a la internación en instituciones o centros de reclusión. Así mismo, advierte acerca de la importancia de consagrar una edad mínima antes de la cual se presumirá que los niños carecen de capacidad para infringir la ley penal, así como la consagración de un sistema especial de jurisdicción penal.

Las Reglas Mínimas para la Administración de la Justicia de Menores o Reglas de Beijing (1985), adoptadas por la Asamblea General de la ONU mediante 
resolución 40/33, agregan a los principios ya expuestos sanciones y reacciones jurídicas distintas a las del confinamiento de menores en establecimientos de reclusión, que faciliten la reintegración de los menores a la sociedad.

Debido a lo anterior, el Código de la Infancia y Adolescencia comprende un conjunto sistematizado de normas, reglas y procedimientos que si bien se ajustan a los parámetros referidos en precedencia, y que en todo caso serían de obligatorio cumplimiento por expresa disposición del régimen jurídico interno, se halla que la normatividad sustancial y procesal no se encuentra de manera íntegra en este código que guía el sistema de responsabilidad penal para adolescentes, sino, contrario sensu, se encuentra dispersa en los tratados y convenios internacionales. Entonces, al ser los anteriores la guía para la interpretación y aplicación, el operador jurídico se encontrará en inconvenientes, pues no solo son los postulados del Código de Infancia y Adolescencia los que debe aplicar. Es por esto que frente al procedimiento debe acudir al Código de Procedimiento Penal; frente a la tipificación de conductas punibles debe acudir al Código Penal; pero además como guía de interpretación y aplicación debe acudir al Convenio de La Haya relativo a la Protección del Niño y a la Cooperación en Materia de Adopción Internacional (1993), desarrollado en la Ley 265 de 1996; la Declaración de los Derechos del Niño (1959); la Convención sobre los Derechos del Niño, incorporada mediante Ley 12 de 1991; las Reglas mínimas de las Naciones Unidas para la administración de la justicia en menores o más conocidas como reglas de Beijing (1985); las Reglas de las Naciones Unidas para la protección de los menores privados de libertad; las Directrices de las Naciones Unidas para la prevención de la delincuencia juvenil (Directrices de Riad), entre otros convenios y tratados internacionales.

La enunciación de los derechos y garantías contenidos en dichas normas no debe entenderse como negación de otras que, siendo inherentes al niño, niña o adolescente, no figuren expresamente en ellas.

El artículo 139 del Código de Infancia y Adolescencia (2006) señala que el sistema de responsabilidad penal para adolescentes es:

(...) el conjunto de principios, normas, procedimientos, autoridades judiciales especializadas y entes administrativos que rigen o intervienen en la investigación y juzgamiento de delitos cometidos por personas que tengan entre catorce (14) y dieciocho (18) años al momento de cometer el hecho punible. (Ley 1098, 2006, art. 139)

Por todo lo anterior, se puede observar que el Sistema de Responsabilidad Penal para Adolescentes está contenido en el Código de Infancia y Adolescencia, pero en el momento de su interpretación y aplicación debe realizarse de 
frente a otras normas de rango internacional, las cuales no contiene ni menciona la Ley 1098 de 2006; por tanto, se genera una necesidad de unificar las normas sustanciales y procesales que direccionan el Sistema de Responsabilidad Penal para Adolescentes, para que así exista certeza jurídica tanto para el operador judicial, como para los fiscales, los defensores y el mismo menor implicado en alguna conducta punible.

\section{NECESIDAD DE UNIFICACIÓN DE NORMAS DEL SISTEMA DE RESPONSABILIDAD PARA ADOLESCENTES}

Ahora bien, una definición básica de unificar es la que indica la Real Academia de la Lengua Española en su primera acepción, que es: «Hacer de muchas cosas una o un todo, uniéndolas, mezclándolas o reduciéndolas a una misma especie». Así las cosas, cuando en la presente investigación se hace referencia al término unificar, se tiene bajo el entendido de armonizar y encauzar hacia un mismo horizonte las normas penales aplicables a los adolescentes, mas no se recomienda compilar en un solo código todas las normas referentes al ámbito penal y de protección del menor, pues sería un desacierto jurídico pretender depositar los tratados internacionales, las leyes nacionales, los tipos penales y los procedimientos en una misma codificación.

Norberto Bobbio (1998, p. 154) indicó que «en realidad los ordenamientos se componen de una miríada de normas que, como las estrellas en el firmamento, son imposibles de contar»; frase acertada al ordenamiento jurídico colombiano, donde cada situación es tratada por el legislador y esta, a su vez, reglamentada por otro sinnúmero de normas.

Sánchez Cordero de García Villegas (2001), en su documento titulado «El futuro del Derecho. Hacia la unificación de las normas procesales como inicio de un salto evolutivo en la justicia», hace un aporte teórico, que es importante frente a la problemática abordada en la presente investigación, pues retomando los conceptos de Bobbio y de Kelsen señala aspectos importantes frente a la unidad del Derecho y la necesidad de la unificación del mismo para tener coherencia, manifestando lo siguiente:

Por mucho tiempo, el derecho pretendió ser entendido y definido mediante el análisis de la norma individualmente considerada, es decir, el objeto principal de estudio de la teoría general del derecho se fundamentaba, exclusivamente, en la norma considerada en sí misma. (Sánchez Cordero, 2001, p. 256)

Sobre lo anterior, Sánchez Cordero (2001, p. 256), citando a Bobbio (1998, p. 154), indica: 
La norma jurídica era la única perspectiva a través de la cual se estudiaba el derecho, dado que el ordenamiento jurídico era, cuando más, un conjunto de normas, mas no un objeto autónomo de estudio, con problemas particulares y diversos. Para expresarlo con una metáfora, se consideraba el árbol, pero no el bosque.

De acuerdo con lo anterior, las normas no pueden verse de manera independiente en el ordenamiento jurídico, pues existirían incoherencias en el momento de la aplicación a los casos concretos. Por tanto, es importante que los postulados normativos en el Estado se encuentren en unidad, coherencia y plenitud según lo indicado por Kelsen, pues, de lo contrario, existiría inseguridad jurídica que crearía injusticia, desigualdad e inequidad social.

Continuando con el documento de la disertación de la ministra Olga Sánchez Cordero de García Villegas, en el ciclo permanente de actualización profesional «Temas relevantes de la práctica procesal en materia civil y familiar», organizado por el Consejo Nacional de Egresados de Posgrado en Derecho a. c., el 19 de marzo de 2001, en la Unidad de Congresos del Centro Médico Nacional, Siglo XXI, en la ciudad de México, indica que:

(...) este concepto de unidad del ordenamiento interno de los Estados, mediante la existencia de una norma fundante básica, ha sufrido en la actualidad una evolución de gran importancia. Los procesos de globalización mundial en las áreas económicas y sociales, han traído como consecuencia el establecimiento de ordenamientos a los que podemos denominar supranacionales.

Esta clase de ordenamientos, condujeron a transformar el concepto de norma fundamental que operaba, en principio, como conservadora de la unidad del ordenamiento jurídico interno de los Estados, hasta un concepto, aún inacabado de norma fundamental, que adquiere una dimensión transnacional y se convierte en creadora y fuente de diversas reglas comunes para los Estados que deciden agruparse siguiendo estos procesos de globalización y unificación. (Sánchez Cordero de García Villegas, 2001, p. 257-258).

Además de armonizar las normas internas, también debe hacerse correspondencia con relación a las normas de Derecho internacional, pues en la globalización del Derecho se da un nuevo principio general en el Derecho, conocido con el nombre de control de convencionalidad, el cual consiste en la prevalencia de los convenios y tratados internacionales de Derechos Humanos, sobre la normatividad interna; incluso, es obligación de los jueces aplicar dicho control en sus providencias, pues la misma jurisprudencia de la Corte 
Interamericana de Derechos Humanos lo ha indicado de manera reiterada. Entre los pronunciamientos de esta Corte se encuentra el siguiente:

Cuando un Estado ha ratificado un tratado internacional como la Convención Americana, sus jueces también están sometidos a ella, lo que les obliga a velar porque el efecto útil de la Convención no se vea mermado o anulado por la aplicación de leyes contrarias a sus disposiciones, objeto y fin. (Caso de los trabajadores cesados del Congreso contra Perú, 2006)

Ahora bien, el artículo 150 de la Constitución Política indica que corresponde al Congreso de la República crear las leyes, y por medio de ellas ejerce entre sus funciones la de «expedir códigos en todos los ramos de la legislación y reformar sus disposiciones» (Constitución Política, 1991, art. 150-2). Por esta razón, la necesidad de la unificación de las normas penales dirigidas a los adolescentes es una función del legislador, gestión en la cual se encuentra indiferente, a pesar de exhortaciones que han realizado entidades como la Corte Constitucional y la Procuraduría General de la Nación.

Si bien es cierto, la Ley 1098 de 2006 logra reconocer como eje de inclusión social a los niños, niñas y adolescentes, como sujetos de derechos y deberes y no simples beneficiarios pasivos de asistencia, porque ellos también son actores y protagonistas del cambio social, por tanto, deben ser responsables de sus actos, de todas aquellas acciones que afecten esa esfera social en la que se encuentran inmersos y de la cual ya tienen un conocimiento básico de lo que se debe y no se debe hacer; frente a lo anterior, el Código de Infancia y Adolescencia logra establecer las pautas para que estos niñas, niños y/o adolescentes se hagan responsables por las acciones que cometen y que son contrarias a las leyes, normas, estatutos y acuerdos internacionales del Estado colombiano.

Pero todo esto, aunque esté bien, no es suficiente, pues se sigue con un Código para menores que pareciera estar incompleto, puesto que a pesar de que establece las «reglas de juego » para el proceso penal en menores, sigue sin ser específico en sus directrices. Por ejemplo, si un menor realiza una conducta típica, antijurídica y culpable, antes de remitirse a la Ley 1098 de 2006, primero se debe acudir a la Ley 599 de 2000 -Código Penal-, para verificar el respectivo delito; posterior a esto, se debe remitir el operador jurídico a la Ley 906 de 2004 -Código de Procedimiento Penal-, para verificar aspectos procedimentales, y así determinar cuál es la pena tasada para este delito; y finalmente volver al Código de Infancia y Adolescencia para verificar cuál es el proceso a seguir con ese menor. Claro; teniendo en cuenta que lo primero que se revisa en el menor son sus datos para comprobar su edad y así poder decidir si puede o no ser llevado a un proceso de responsabilidad penal. Entonces, para someter a un adolescente al sistema de Responsabilidad Penal, se debe tener de presente 
el Código Penal, el Código de Procedimiento Penal, el Código de Infancia y Adolescencia, y sin lugar a dudas la Constitución Política; pero se suman a ello los tratados internacionales que en virtud del control de convencionalidad deben ser tenidos en cuenta sobre la legislación nacional, siendo así para el operador judicial, un trabajo más tedioso del que realmente debería ser, teniendo en cuenta que ya existe un Código para menores, que busca, además de salvaguardar sus derechos, hacer responsable al menor de sus deberes como parte de la sociedad en la que se desarrolla.

Aunque notoriamente el proceso de Responsabilidad Penal para Adolescentes es mucho más riguroso que el sistema penal para adultos en cuanto al desarrollo del mismo, verbigracia desde el inicio solo con la detención de adolescente, el art. 37, inciso b) de la Convención sobre los Derechos del Niño (1989) prohíbe la detención ilegal o arbitraria de un adolescente. Dado el caso que se concrete la detención, debe seguirse el procedimiento legal, esta debe ser utilizada como medida de último recurso y extenderse durante el menor tiempo posible, lo que implica que en este caso el fiscal justifique debidamente la improcedencia, la imposibilidad de aplicar o la ineficacia de otras medidas alternativas a la privación de libertad que cumplan con los fines cautelares; esto no deja de cruzarse con el sistema para adultos, y como se ha dicho antes, esta rigurosidad sumada a la constante remisión que hace la Ley 1098 de 2006, al Código Penal y el Código de Procedimiento Penal, hace del trabajo del operador judicial una pérdida de valioso tiempo y hasta lo podría llevar a errores en su proceder como funcionario.

Una sentencia importante proferida por la Corte Constitucional, es la C-684 de 2009, en la que el alto tribunal exhorta al Congreso de la República para que expida un proceso penal especial para el adolescente; esto indica la corporación:

(...) Dado el alto grado de indeterminación normativa verificado en el precepto acusado, del cual se derivan importantes obstáculos para el ejercicio del derecho de defensa y contradicción de los adolescentes sorprendidos en flagrancia y que en cierta medida también desnaturalizan la presunción de inocencia, y habida cuenta del mandato contenido en el principio de legalidad en materia penal y los principios de especificidad y diferenciación que rigen el sistema de responsabilidad penal de los adolescentes, la Corte encontró viable exhortar al Congreso de la República para que revise la cuestión y decida la necesidad de expedir una normativa que regule el procedimiento para la investigación y juzgamiento de los adolescentes sorprendidos en flagrancia. (Sentencia C-684, 2009)

Coadyuvando la posición anterior, el procurador general de la Nación, mediante concepto nro. 4786, radicado el dos (02) de junio de dos mil nueve 
(2009), solicita que se exhorte al Congreso para que en la próxima legislatura expida el Proceso Penal Especial para el Adolescente, añadiendo lo siguiente:

Estima el Procurador que debido a las numerosas falencias procesales en que incurrió el legislador al reglamentar el proceso penal para los adolescentes, sumadas a «la importancia de los derechos fundamentales puestos en riesgo y la necesidad de garantizar el principio de seguridad jurídica», se requiere la expedición de «una nueva legislación que con detenimiento y rigurosidad se centre en la judicialización de los menores infractores de la ley penal y que a su vez garantice los principios del interés supremo del adolescente, la prevalencia de sus derechos, la protección integral y el derecho a tener una familia y no ser separado de ella», razón por la cual solicita a la Corte Constitucional exhorte al Legislador para que en la próxima legislatura expida el Proceso Penal Especial para el Adolescente acogiendo las recomendaciones de las Reglas de Beijing y de la Corte Interamericana de Derechos Humanos. (Sentencia C-684, 2009)

Sobre el tema sub examine, es la C-876 de 2011, de acuerdo al Concepto nro. 5180 recibido en la Corte Constitucional el 7 de julio de 2011, la Procuraduría General de la Nación, nuevamente muestra la necesidad de que se unifiquen las normas direccionadas a los niños, niñas y adolescentes, indicando lo siguiente:

Con base en los argumentos expuestos el Ministerio Público solicita a la (....) exhortar al Congreso de la República para que todo lo relativo a la protección de los derechos de los niños, niñas, adolescentes, unifique y actualice la legislación penal, civil, comercial y laboral conforme a lo dispuesto en los instrumentos internacionales de derechos humanos. (Sentencia C-876, 2011)

La Procuraduría General de la Nación, mediante oficio de fecha 30 de mayo de 2012, enviado para el proceso de revisión constitucional del Proyecto de Ley Estatutaria 169 de 2011, Senado -084 de 2011 Cámara, «por medio de la cual se expide el Estatuto Ciudadano Juvenil y se dictan otras disposiciones», dentro del estudio que realiza a dicho proyecto de Ley Estatuaria, vuelve a señalar su intención de la necesidad de unificación de las normas de infancia y adolescencia frente a su interpretación y aplicación al expresar que «(...) esta Jefatura insistirá en lo relativo a su armonización y unificación con las normas y criterios constitucionales e internacionales, lo que también entiende como necesario para cumplir con los enfoques de interpretación y aplicación de la Ley Estatutaria que se propone en el artículo $3 .^{\circ}$ del Proyecto» el cual indica «las normas contenidas en la Constitución Política y en los Tratados o Convenios Internacionales de Derechos Humanos ratificados por Colombia, en especial la Convención sobre los Derechos del Niño en lo que les es aplicable, harán parte 
integral de esta ley, y servirán de guía para su interpretación», a lo cual, dicha entidad insiste:

(...) si el Congreso de la República desea reglamentar por vía de Ley Estatutaria los derechos y deberes de los jóvenes, entre otras disposiciones, debe hacerlo de conformidad con las normas pertinentes del bloque de constitucionalidad y unificando, si es el caso, las leyes ordinarias relativas a esas mismas temáticas en lo que resulte pertinente. (Procuraduría General de la Nación , 2012)

Con lo anterior, se tiene que la Procuraduría General de la Nación ha sido insistente en hacer el llamado al Congreso de la República de Colombia para que unifique las normas de infancia y adolescencia para así facilitar la interpretación y aplicación en los respectivos casos particulares.

La Corte Constitucional, al realizar el análisis de varios casos particulares, ha exhortado también al Congreso de la República para que regule el procedimiento para la investigación y el juzgamiento de los adolescentes.

Es de importancia dicha unificación con el fin de tener certeza en los tipos de penas a aplicar, los mínimos y máximos para cada tipo penal, y en general todos los procedimientos encaminados al ejercicio del ius puniendi por parte del Estado colombiano frente a los menores infractores.

\section{CONCLUSIONES}

Unificar, según la RAE, es hacer de muchas cosas una o un todo, uniéndolas, mezclándolas o reduciéndolas a una misma especie.

En la presente investigación unificar se tiene bajo el entendido de armonizar y encauzar hacia un mismo horizonte las normas penales aplicables a los adolescentes; mas no es compilar todas las normas en un solo Código.

En efecto, como lo señalaba Hans Kelsen, todo ordenamiento jurídico se basa en tres conceptos fundamentales: la unidad, la coherencia y la plenitud.

El sistema de responsabilidad penal para adolescentes es un conjunto de normas, principios y procedimientos, que además señala las autoridades judiciales especializadas y los entes administrativos que rigen o intervienen la investigación y juzgamiento de delitos cometidos por menores entre 14 y 18 años.

El Sistema de Responsabilidad Penal para adolescentes tiene la finalidad de imponer medidas de carácter pedagógico, específico y diferenciado, respecto del sistema de adultos. 
Las sanciones que se imponen a los adolescentes infractores son la amonestación, la imposición de reglas de conducta, la prestación de servicios a la comunidad, la libertad asistida, la internación en medio semicerrado y la privación de libertad en centro de atención especializado.

El Código de Infancia y Adolescencia para su aplicación se vale de la remisión al Código de Procedimiento Penal; frente a la tipificación de conductas punibles debe acudir al Código Penal, pero además como guía de interpretación y aplicación debe acudir al Convenio de La Haya relativo a la Protección del Niño y a la Cooperación en Materia de Adopción Internacional, Declaración de los Derechos del Niño, Convención sobre los Derechos del Niño, Reglas mínimas de las Naciones Unidas para la administración de la justicia en menores o más conocidas como reglas de Beijing, Reglas de las Naciones Unidas para la protección de los menores privados de libertad, Directrices de las Naciones Unidas para la prevención de la delincuencia juvenil (Directrices de Riad), entre otros convenios y tratados internacionales.

El Código de Infancia y Adolescencia remite al intérprete y al operador judicial a otras normas como son el Código Penal, el Código de Procedimiento Penal, y los tratados y convenios internacionales, haciendo esto una dificultad en la interpretación y aplicación de la norma.

Se requiere que el Congreso de la República unifique un Código de infancia y adolescencia en donde indique los mínimos y máximos de aplicación de sanciones a los menores de acuerdo al tipo penal cometido, pues hasta el momento se realiza sin un criterio de igualdad, pues la norma da la potestad al operador judicial para aplicar el tiempo que considere según la gravedad de la infracción penal.

La Procuraduría General de la Nación y la Corte Constitucional han exhortado al Congreso de la República de Colombia desde el año 2009 para que realice una unificación de las normas de infancia y adolescencia y fije criterios frente al procedimiento de investigación y juzgamiento de los adolescentes que transgreden las normas penales; sin embargo, el legislador ha sido renuente en dicha instrucción dada por estas altas entidades.

Finalmente, la Procuraduría General de la Nación no ha insistido solamente en la unificación de las normas en materia penal, sino también ha ido más allá, al indicar la imperiosa necesidad de que se unifique y actualice la legislación penal, civil, comercial y laboral conforme a lo dispuesto en los instrumentos internacionales de derechos humanos. 


\section{REFERENCIAS}

Asamblea General de la ONU. (20 de noviembre de 1959). Declaración de los Derechos del Niño. Resolución 1386 (XIV).

Asamblea General de la ONU. (16 de diciembre de 1966). Pacto Internacional de Derechos Civiles y Políticos. Resolución 2200 A (XXI).

Asamblea General de la ONU. (20 de noviembre de 1989). Convención sobre los Derechos del Niño. Resolución 44/25.

Asamblea General de la ONU. (14 de diciembre de 1990). Reglas de las Naciones Unidas para la protección de los menores privados de libertad. Resolución 45/113.

Asamblea General de la ONU. (28 de noviembre de 1985). Reglas mínimas de las Naciones Unidas para la administración de la justicia de menores. Resolución 40/33.

Asamblea Nacional Constituyente. (1991). Constitución Política. Bogotá D. C.

Berríos Díaz, G. (2005). El nuevo sistema de justicia penal para adolescentes. Revista de Estudios de la Justicia, nro. 6.

Bobbio, N. (1998). Teoría general del Derecho. Madrid: Debate.

Bustos Ramírez, J. (1997). Perspectivas de un derecho penal del niño. Nueva Doctrina Penal. Buenos Aires: Ed. del Puerto.

Conferencia de La Haya. (29 de mayo de 1993). Convenio de La Haya relativo a la Protección del Niño y a la Cooperación en materia de Adopción Internacional.

Corte Interamericana de Derechos Humanos. (24 de noviembre de 2006). Caso de los trabajadores cesados del Congreso contra Perú, Sentencia de noviembre 24 de 2006.

Congreso de la República de Colombia. (26 de diciembre de 1968). Ley 74. Por la cual se aprueban los Pactos Internacionales de Derechos Económicos, Sociales y Culturales, de Derechos Civiles y Políticos, así como el Protocolo Facultativo de este último, aprobado por la Asamblea General de las Naciones Unidas. Bogotá D. C.

Congreso de la República de Colombia. (30 de diciembre de 1972). Ley 16. Por medio de la cual se aprueba la Convención Americana sobre Derechos Humanos. «Pacto de San José de Costa Rica», firmado en San José, Costa Rica. Bogotá D. C., Colombia.

Congreso de la República de Colombia. (22 de enero de 1991). Ley 12. Por medio de la cual se aprueba la Convención sobre los Derechos del Niño adoptada por la Asamblea General de las Naciones Unidas el 20 de noviembre de 1989. Bogotá D. C., Colombia. 
Congreso de la República de Colombia. (25 de enero de 1996). Ley 265. Por medio de la cual se aprueba el "Convenio relativo a la protección del niño y a la cooperación en materia de adopción internacional», suscrito en La Haya, el 29 de mayo de 1993. Bogotá D. C., Colombia.

Congreso de la República de Colombia. (08 de noviembre de 2006). Ley 1098. Por la cual se expide el Código de la Infancia y la Adolescencia. Bogotá D. C.

Convención Americana sobre Derechos Humanos. (22 de noviembre de 1969). San José, Costa Rica.

Corte Constitucional de Colombia. (30 de septiembre de 2009). Sentencia C-684 de 2009. M. P. Dr. Humberto Antonio Sierra Porto.

Corte Constitucional de Colombia. (22 de noviembre de 2011). Sentencia C-876 de 2011. M. P. Mauricio González Cuervo.

Directrices de las Naciones Unidas para la prevención de la delincuencia juvenil (Directrices de Riad). (14 de diciembre de 1990). Resolución 45/112.

Procuraduría General de la Nación. (07 de julio de 2011). Concepto 5180. Expediente D-8520. Demanda de inconstitucionalidad contra algunas expresiones de los artículos 208 y 209 de la Ley 599 de 2000, «Por la cual se expide el Código Penal». Bogotá D. C.

Procuraduría General de la Nación. (30 de mayo de 2012). Concepto 5376. Expediente PE-034. Revisión constitucional del Proyecto de Ley Estatutaria 169 de 2011 Senado 084 de 2011 Cámara, «por medio de la cual se expide el Estatuto Ciudadano Juvenil y se dictan otras disposiciones». Bogotá D. C.

Real Academia Española. (s. f.). Diccionario de la lengua española. Recuperado el 20 de

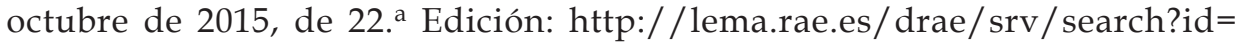
bZufBG6IVDXX2k1a9SJG

Sánchez Cordero de García Villegas, O. (2001). El futuro del Derecho. Hacia la unificación de las normas procesales como inicio de un salto evolutivo en la justicia. Recuperado el 20 de octubre de 2015, de http://www.juridicas.unam.mx/publica/librev/rev/ anjuris/cont/250/pr/pr8.pdf 
